INTERNACIONAL

\title{
El derecho a la indemnización por error judicial y la responsabilidad patrimonial del Estado para hacer efectivo el acceso a la justicia: El caso de México
}

\author{
The right to compensation for miscarriage of justice and the patrimonial responsibility \\ of the State to ensure effective access to justice: The case of Mexico
}

\author{
María Chiara Marullo \\ Universidad Jaime I, España \\ Jessica Cristina Romero \\ Universidad de Colima, México
}

RESUMEN El derecho de acceso a la justicia, derecho humano y principio básico del Estado de derecho es esencial para garantizar un desarrollo sostenible y sociedades más justas y pacíficas. Para asegurar su efectividad, los Estados deben implementar medidas para salvaguardar, entre otros, derechos, garantías y protección judicial. Por esta razón, debemos referirnos a la agenda de Naciones Unidas sobre los objetivos de desarrollo sostenible, particularmente el objetivo 16, acceso a la justicia, para hacer una crítica respecto de la creación de estrategias y acciones en un tema que se ha omitido por el legislador mexicano, la indemnización por error judicial, ya que el marco legal y de interpretación no contribuye a exigirle al Estado una responsabilidad directa y objetiva por los daños causados a una persona que ha sido privada de su libertad injustamente.

PALABRAS CLAVE Acceso a la justicia, indemnización, error judicial, responsabilidad patrimonial del Estado, México.

ABSTRACT The right of access to justice, human right and basic principle of the rule of Law, is essential to guarantee a sustainable development and more just and peaceful societies. To ensure its effectiveness, States must implement measures to safeguard, among others, rights, guarantees and judicial protection. This is why we must refer to the UN Agenda on the Sustainable Development Goals, particularly objective 16, access to justice, to make a criticism regarding the creation of strategies and actions on 
a topic that has been omitted by the Mexican legislator: compensation for miscarriage of justice. This is because the legal and interpretative framework does not contribute to demanding from the State a direct and objective responsibility for the damages caused to those who have been deprived of their freedom unjustly.

KEYWORDS Access to justice, compensation, miscarriage of justice, patrimonial responsability of the State, Mexico.

\section{Introducción}

En el ámbito internacional, hemos avanzado en la idea de que el acceso a la justicia, como derecho humano y principio básico del Estado de derecho, sea esencial para garantizar un desarrollo sostenible y sociedades más justas y pacíficas. ${ }^{1}$ Su proclamación la convierte en una garantía indispensable para el ejercicio de otros derechos humanos reconocidos en convenios internacionales, y debe ser acompañada de los mecanismos para que su tutela sea efectiva. ${ }^{2}$ Por ello, los Estados -incluido México- deberían estar implementando acciones derivadas de los objetivos de desarrollo sostenible, en el que los Estados se comprometen a crear medidas más eficaces que derivan, incluso, de los convenios internacionales ratificados y ampliamente aceptados.

Por esta razón, creemos que, desde la perspectiva de la agenda de las Naciones Unidas, podemos hacer una crítica sobre la creación de estrategias y acciones para garantizar este derecho, como la indemnización por error judicial, que ha sido omitida por el legislador mexicano. El problema planteado se genera porque en México $^{3}$ el marco legal y de interpretación no contribuye a exigirle al Estado una responsabilidad directa y objetiva por los daños y perjuicios causados por la administración de justicia, específicamente cuando una persona ha sido condenada y resultó injustamente privada de la libertad a causa de un error (Rodríguez Ramos, 2016; Zúñiga

1. «Objetivo 16: Promover sociedades justas, pacíficas e inclusivas», sitio web de Objetivos de Desarrollo Sustentable de Naciones Unidas, disponible en http://bit.ly/2NXGyRE. Véase también «Report of the Special Rapporteur on extreme poverty and human rights», Asamblea General de Naciones Unidas, 9 de agosto de 2012, A/67/278, disponible en http://bit.ly/2q2ZWD6.

2. «El Estado tiene que organizar todo su aparato estatal para asegurar las garantías de debido proceso y el acceso a un recurso judicial efectivo». Corte Interamericana de Derechos Humanos, Opinión Consultiva 11, sobre «Excepciones al agotamiento de los recursos internos (artículos 46.1, 46.2.a y 46.2.b, Convención Americana sobre Derechos Humanos)», 1989, párrafo 24.

3. En agosto de 2015 se sumó México (Rodríguez Barba, 2016; Lozano y otros, 2015). Véase también, «Joint statement to the Open Working Group on the Sustainable Development Goals (SDGs)», sitio web de Objetivos de Desarrollo Sustentable de Naciones Unidas, 6 de febrero de 2014, disponible en http:// bit.ly/2NWBZHh. 
Urbina, 2008). La vía alterna que se preveía, antes de constitucionalizar la responsabilidad patrimonial del Estado, era la de responsabilidad profesional o legal, esto es, civil o penal, acreditando el elemento subjetivo para exigir indirectamente al Estado la reparación de daños. Esta vía fue, sin embargo, derogada.

Nuestro propósito es analizar que el estatuto objetivo de responsabilidad del Estado sería una de las vías más eficaces y eficientes para cumplir con las obligaciones internacionales ratificadas en el Pacto de San José, entre otros, para garantizar y priorizar el acceso a la justicia en todos los niveles. Como un avance descriptivo de este proceso, incorporamos la última reforma que en materia penal se está implementando, misma que no acotamos por los límites de esta investigación.

\section{Acceso a la reparación como objetivo de desarrollo sostenible}

Es en el sector de la cooperación para el desarrollo donde la justicia está asumiendo un rol central, si consideramos la estrecha relación entre el desarrollo humano y la erradicación de la pobreza. Efectivamente, en esta área asistimos a un cambio en el entendimiento conceptual de acceso a la justicia como un factor que puede incidir y como una capacidad para prevenir y superar la pobreza, mediante la búsqueda y la utilización de mecanismos propios del sistema de justicia, conforme a los principios y normas de protección de los derechos humanos.

Por ello, los Estados están comprometidos en la implementación de medidas más eficaces, en los que el acceso a la justicia se considere una prioridad para garantizar otros derechos humanos. El decimosexto de los objetivos de desarrollo sustentable extiende el acceso a la justicia a todos los niveles, desde la persecución de delitos hasta la reparación de daños, y hace responsables a las instituciones por crear sociedades más pacíficas e inclusivas, con el fin de reducir la pobreza y otras formas de discriminación y desigualdades.

La meta 16.3 construye el concepto de acceso a la justicia conforme a lo previsto en el artículo 8 de la Declaración Universal de los Derechos Humanos: «Cualquiera tiene derecho a un recurso efectivo ante los tribunales nacionales competentes por actos que violen los derechos fundamentales que le otorga la Constitución o por ley». $\mathrm{Su}$ objetivo es garantizar que los países cuenten con leyes y sistemas de justicia efectivos, justos y accesibles, que brinden seguridad y protección a todas las personas.

Sobre este aspecto, cabría valorar si los compromisos internacionales, que derivan de los tratados internacionales para garantizar los derechos fundamentales, están siendo cumplidos, en particular el acceso a la justicia en términos de reparación de daños que pudieran producirse por actuación de órganos estatales en el ejercicio de sus funciones. 


\section{El acceso a la justicia y el derecho a una indemnización en las normas internacionales}

Las obligaciones internacionales relativas a la persecución, castigo y reparación de graves violaciones de normas imperativas del derecho internacional ${ }^{4}$ demuestran la necesidad de que los Estados cumplan con el más genérico de los principios: garantizar mecanismos efectivos y eficaces en el acceso a la justicia, consolidado como un derecho fundamental y, al mismo tiempo, garante de otros derechos contenidos en las constituciones modernas y en los tratados internacionales, respaldado por los tribunales internacionales. Así lo refiere la Corte Europea de Derechos Humanos en el caso Mentes con Turquía, pues interpretando el artículo 13 del Convenio Europeo de Derechos Humanos, señala que es obligación de los Estados la implementación de un recurso efectivo que permita al individuo reclamar cuando sus derechos han sido violados. ${ }^{5}$

El problema surge cuando falta o se obstaculiza el derecho a tener acceso a un foro adecuado, lo cual hace que los actores involucrados en las violaciones queden impunes y no se garantice una adecuada indemnización por lo sufrido. Conscientes de esto, Naciones Unidas aprobó la resolución A/RES/6o/147 del 24 de octubre de 2005, referida a los «Principios y directrices básicos sobre el derecho de las víctimas de violaciones de las normas internacionales de derechos humanos y del derecho internacional humanitario a interponer recursos y obtener reparaciones». ${ }^{6}$

Ahora bien, para garantizarlo, los Estados deben establecer mecanismos efectivos y eficaces para reparar los daños y perjuicios sufridos. ${ }^{7}$ De hecho, podemos decir que no existe justicia si no se garantiza una efectiva reparación. Si el derecho de acceso a la justicia es un derecho a los recursos judiciales, enmarcado en el derecho procesal, entonces está vinculado al derecho sustancial de la indemnización de los daños, que

4. La norma del artículo 4o del proyecto de la Comisión de Derecho Internacional sobre la Responsabilidad Internacional de los Estados establece: «1) El presente capítulo se aplicará a la responsabilidad internacional generada por una violación grave por el Estado de una obligación que emane de una norma imperativa del derecho internacional general. 2) La violación de tal obligación es grave si implica el incumplimiento flagrante o sistemático de la obligación por el Estado responsable». Proyecto de artículos sobre la responsabilidad del Estado por hechos internacionalmente ilícitos aprobados por el Comité de Redacción en Segunda Lectura, A/CN.4/L.602/Rev.1, 26 de julio de 2001.

5. Sentencia del caso Mentes con Turquía, Corte Europea de Derechos Humanos, 28 de noviembre de 1997.

6. Resolución 60/147, aprobada por la Asamblea General el 16 de diciembre de 2005, disponible en http://bit.ly/2NYfWzP.

7. En esta línea, el Comité de los Derechos Humanos, en el caso Bautista de Arellana con Colombia, decidió en el párrafo 8.2: «Los recursos administrativos no pueden considerarse recursos adecuados y eficaces [...] particularmente en casos de graves violaciones a los derechos humanos [...]» (La traducción es nuestra). 
restablece a la situación que habría existido si el acto no se hubiese cometido. Así se pronunció la entonces Corte Permanente Internacional de Justicia en 1927: «Es un principio del derecho internacional que el incumplimiento de un compromiso implica una obligación de reparar de forma adecuada». ${ }^{8}$

Sobre este aspecto, el principio 9 de las directrices básicas sobre el derecho de las víctimas de violaciones de las normas internacionales de derechos humanos de la Asamblea General de Naciones Unidas establece:

Reparación de los daños sufridos: Una reparación adecuada, efectiva y rápida tiene por finalidad promover la justicia, remediando las violaciones manifiestas de las normas internacionales de derechos humanos [...]. La reparación ha de ser proporcional a la gravedad de las violaciones y al daño sufrido. [...] Cuando se determine que una persona física o jurídica u otra entidad está obligada a dar reparación a una víctima, la parte responsable deberá conceder reparación a la víctima o indemnizar al Estado si éste hubiera ya dado reparación a la víctima (Resolución 6o/147).

Asimismo, el Tribunal Europeo de Derechos Humanos, en el caso Jabari con Turquía, señaló que «el derecho al recurso efectivo debe garantizar un medio/instrumento a través del cual los justiciables puedan obtener la reparación de las violaciones de sus derechos garantizados por la Convención». ${ }^{9}$

La reparación es central en la mayoría de tratados internacionales sobre prevención, sanción y reparación de graves violaciones cometidas en contra de los derechos humanos, como la Convención para la Prevención y Sanción del Delito de Genocidio; la Convención sobre la Imprescriptibilidad de los Crímenes de Guerra y de los Crímenes de Lesa Humanidad; la Convención contra la Tortura y Otros Tratos Crueles, Inhumanos y Degradantes; y la Convención Americana sobre Derechos Humanos, que establece en los artículos 10 y 63.1 el derecho a ser indemnizado conforme a la ley, así como el artículo 68, que refiere a la indemnización compensatoria. Asimismo, la jurisprudencia de la Corte Interamericana de Derechos Humanos, en González y otras (Campo Algodonero) con México, estableció: «Es un principio de derecho internacional que toda violación de una obligación internacional que haya producido daño comporta el deber de repararlo adecuadamente. Esa obligación se regula por el derecho internacional». ${ }^{10}$

Cuando la violación conlleva a un arresto o detención ilegal, existen tratados in-

8. Sentencia del caso Factory at Chorzow, Corte Permanente Internacional de Justicia, series a, número 9, 26 de Julio de 1927, disponible en https://bit.ly/2yVINjv.

9. Sentencia del caso Jabari con Turquía, Tribunal Europeo de Derechos Humanos, 11 de julio de 200o, párrafo 48. En el mismo sentido: sentencia del caso Kudla con Polonia, Tribunal Europeo de Derechos Humanos, 20 de octubre de 200o, párrafo 152.

10. Sentencia del caso González y otras (Campo Algodonero) con México, Corte Interamericana de Derechos Humanos, 16 de noviembre de 2009, párrafo 446. 
ternacionales que establecen los derechos de la víctima de uno de estos actos y la responsabilidad del Estado y los otros actores involucrados en dichas violaciones. De hecho, la Convención Europea de Salvaguardia de los Derechos del Hombre y Libertades Fundamentales, en su artículo 5, inciso quinto establece: «Toda persona víctima de un arresto o detención contrarios a las disposiciones de este artículo tendrá derecho a una reparación». Igualmente, el Pacto Internacional de Derechos Civiles y Políticos, en su artículo 14, párrafo 6 establece:

Cuando una sentencia condenatoria firme haya sido ulteriormente revocada, o el condenado haya sido indultado por haberse producido o descubierto un hecho plenamente probatorio de la comisión de un error judicial, la persona que haya sufrido una pena como resultado de tal sentencia deberá ser indemnizada conforme a la ley.

Ese principio ha sido interpretado en la jurisprudencia del Tribunal Europeo, como en el caso Poghosyan y Baghdasaryan con Armenia, en el que sentenció una indemnización por parte del Estado por errores judiciales que tuvieron como consecuencia daños morales. ${ }^{11}$ También el Comité de Derechos Humanos, en Griffin con España, estableció que el Estado español deberá pagar una compensación apropiada por el periodo en que estuvo en prisión en Melilla. ${ }^{12}$

Se confirma entonces que, si la violación de los derechos fundamentales consistió en una privación ilegal de la libertad, el Estado que vulneró este derecho deberá indemnizar a la víctima por el daño. En ese sentido, la responsabilidad de los Estados no puede ser limitada a ningún aspecto de la actividad estatal, sino extenderse a la actividad de los poderes públicos.

\section{El caso de México}

El marco legal y de interpretación no contribuye a exigirle al Estado una responsabilidad directa y objetiva cuando los órganos encargados de impartir justicia llegan a causar daños por error judicial, con lo cual incumplen en el respeto de las garantías judiciales y el derecho de indemnización, además de la falta de implementación de acciones derivadas del decimosexto de los objetivos de desarrollo sostenible.

En las actuaciones del Gobierno en el ámbito federal, el marco legal no ha cumplido con adecuar las normas internas o expedir aquéllas que permitan el desarrollo de prácticas para tutelar el derecho humano a la indemnización derivada de un error judicial, consagrado en el Pacto Internacional de Derechos Civiles y Políticos, artículo 9 inciso quinto y artículo 14 inciso sexto, así como en la Convención Americana

11. Sentencia del caso Poghosyan y Baghdasaryan con Armenia, Tribunal Europeo de Derechos Humanos, 12 de junio de 2012.

12. Sentencia del caso Griffin con España, Comité de Derechos Humanos, 5 de abril de 1995. 
sobre Derechos Humanos, artículo 10. Ni siquiera como consecuencia de la reforma al artículo 1 constitucional del 10 de junio de 2011, cuando reconoció como derechos fundamentales a los contenidos en los tratados internacionales de los que es parte. Se generó así una antinomia entre este artículo y el artículo 109, último párrafo, que dispone que la responsabilidad patrimonial del Estado solo garantiza el derecho a la indemnización procedente de daños ocasionados por la Administración Pública.

Sobre este tema, la Suprema Corte de Justicia se pronunció resolviendo, en el posicionamiento de las normas sobre derechos humanos contenidos en tratados internacionales en relación con la Constitución, que «cuando la Constitución establezca una restricción expresa al ejercicio de los derechos humanos, se deberá estar a lo que indica la norma constitucional». ${ }^{13}$ De esta manera, ratifica un obstáculo para acceder a la justicia por daños ocasionados por el Estado derivados del mal ejercicio de sus autoridades al impartir justicia, y en contravención a las obligaciones que adquirió, previstas en los artículos 2, incisos primero y segundo del Pacto Internacional de Derechos Civiles y Políticos; y los artículos 1, 2 y 29 de la Convención Americana de Derechos Humanos, pues el compromiso involucra a todos los órganos estatales, y si sus disposiciones no garantizan los derechos humanos, éste con arreglo a sus procedimientos constitucionales debería adoptar las medidas que fueran necesarias, ya que un error judicial produce daños, lo que configura la responsabilidad patrimonial del Estado, garantía que no puede ni debe limitarse exclusivamente a las actuaciones $\mathrm{u}$ omisiones administrativas.

Como un mínimo avance, se han comenzado a introducir derechos en sus disposiciones federales en materia penal, como el Código Nacional de Procedimientos Penales, cuyo artículo 490 establece una indemnización en caso de reconocimiento de inocencia cuando una persona ha sido privada de su libertad durante el desarrollo del procedimiento.

No obstante, dicha reforma por sí sola no resulta suficiente, pues como norma pragmática no disciplina todos los aspectos, lo que deja al ámbito local la potestad de legislar, lo que a su vez menoscaba las posibilidades para las personas que no tienen la obligación jurídica de soportar un error judicial, y por tanto vean limitado su acceso a la justicia y reclamar una indemnización, especialmente cuando no hay reglamentación para que el mecanismo sea efectivo y eficiente.

En este supuesto, cuando una persona ha sufrido prisión preventiva, al concluir el procedimiento penal, si se le absuelve o se dicta sobreseimiento - queda libre por inexistencia del hecho imputado-, para que el Estado la indemnice, debe acreditar el perjuicio ocasionado y la cuantía que dependerá del tiempo de privación de libertad,

13. «Contradicción de tesis 293/2011: SCJN determina que las normas sobre derechos humanos contenidas en tratados internacionales tienen rango constitucional», Suprema Corte de Justicia de la Nación, disponible en http://bit.ly/2Ralhol. 
así como las consecuencias patrimoniales que se hayan producido. Además, para que proceda se debe acreditar: ${ }^{14}$

- Que haya sufrido prisión preventiva.

- La sentencia absolutoria o auto de sobreseimiento libre por inexistencia del hecho, que exista: i) el elemento material, que es la inexistencia del hecho, que comprende tanto los casos de inexistencia objetiva del hecho, como los casos de inexistencia subjetiva, esto es, que no hubiera sido constitutivo de delito, o bien imposibilidad de participación en tal hecho; y ii) el elemento formal, que consiste en la sentencia absolutoria o el auto de sobreseimiento libre o provisional.

- Se hayan irrogado perjuicios referentes a la prisión preventiva y cualesquiera otras medidas cautelares adoptadas.

Analizando la reforma, el Código Nacional de Procedimientos Penales prevé en el artículo 490 el derecho a la indemnización: en caso de que se dicte reconocimiento de inocencia, se resolverá de oficio la indemnización que proceda en términos de las disposiciones aplicables, en donde el reconocimiento de inocencia está limitado a lo previsto en el artículo 486, que dice:

Procederá cuando después de dictada la sentencia aparezcan pruebas de las que se desprenda, en forma plena, que no existió el delito por el que se dictó la condena o que, existiendo éste, el sentenciado no participó en su comisión, o bien cuando se desacrediten formalmente, en sentencia irrevocable, las pruebas en las que se fundó la condena (los destacados son nuestros).

Supuestos que corresponden al elemento material que debe acreditarse, lo que demuestra la inexistencia objetiva del hecho, así como los casos de inexistencia subjetiva, esto es, que no hubiera sido constitutivo de delito, o bien por la imposibilidad de participación en el hecho.

Sin embargo, estos supuestos no dejan espacio a formas absolutorias, dudosas o de prescripción del delito. $\mathrm{Al}$ respecto, Mosset Iturraspe señala que, para encuadrar al error judicial, se le tiene que analizar desde el enfoque de cómo se generó el error, es decir, si éste es espontáneo, «al cual llega el juez por sí, sin la intervención de un tercero», o si es provocado, esto es «la equivocación a la cual es llevado el juez por obra o conducta de terceros». "Así, el "error judicial" puede ser [...] el resultado de la equivocación propia, de los conceptos falsos que se poseen, o la consecuencia de la actitud dolosa de las partes en el proceso o de un tercero» (Mosset Iturraspe, 2003: 80; citado por Romero Michel, 2013: 119).

14. Sentencia del Tribunal Supremo de España, 13 de noviembre de 2000 (Aranzadi 200/142). 


\section{Comparativamente, el Tribunal Supremo Español dijo:}

El error judicial debe proceder de una resolución injusta o equivocada, viciada de un error craso, patente, indubitado o incontestable, que haya provocado conclusiones fácticas o jurídicas ilógicas, irracionales, esperpénticas o absurdas, que rompan con la armonía del orden jurídico, resultando de actuaciones realizadas abiertamente fuera de los cauces legales (González Alonso, 2008: 164).

Pero digamos que el código deja abierta la posibilidad a los casos en que las pruebas, sobre las cuales se fundó la condena, hayan sido tomadas de forma ilegal, como podría ser una confesión bajo tortura y sin respeto de las normas sobre la representación legal y la protección de los de derechos del acusado. Igualmente, el Código Nacional de Procedimientos Penales prevé que la indemnización se tramitará en apelación y se resolverá de oficio por el Tribunal de Alzada en la misma sentencia que dicte el reconocimiento de inocencia, de acuerdo con el trámite previsto en los artículos 488 y 489 . Esto significa que deberá promoverse en un término de cinco días, ${ }^{15}$ y si protestó exhibir las pruebas correspondientes, se le otorgará un plazo no mayor a diez días, tiempo muy limitado para ofrecer las pruebas que lo acrediten, además de la declaración de inocencia, lo correspondiente a los daños y perjuicios sufridos durante el tiempo en que estuvo privado de la libertad. En cambio, si lo equiparamos con la naturaleza jurídica del error judicial, tendríamos la posibilidad de llevar a cabo el trámite a través del procedimiento administrativo que se sigue de conformidad con las normas que regulan la responsabilidad patrimonial del Estado, ${ }^{16}$ en el que la acción para obtener la indemnización prescribe en un año a partir del día en que pudo ejercitarse y, para este caso, el plazo comenzaría desde que el error judicial fue declarado en la sentencia de inocencia.

En cuanto a la indemnización, se dictará en términos de las disposiciones aplicables. Las preguntas que nos hacemos son: ¿cuáles disposiciones?, ¿cuáles serían los criterios que el Tribunal de Alzada podría utilizar para determinar la forma y el quantum?, ¿cuáles serían las posibilidades para que la persona afectada pueda recibir una indemnización?

Por ejemplo, en las disposiciones del ámbito federal, la responsabilidad patrimonial del Estado no opera. Tratándose de indemnización, tendríamos que invocar disposiciones de responsabilidad profesional o legal, esto es, civil o penal, para exigirla indirectamente al Estado, como reparación extracontractual por actos del Estado, la

15. De conformidad con el artículo 471 del Código Nacional de Procedimientos Penales.

16. En el caso de España, este procedimiento está previsto en los artículos 139 y siguientes de la Ley Régimen Jurídico de las Administraciones Públicas y del Procedimiento Administrativo Común y del Reglamento de los Procedimientos de las Administraciones Públicas en materia de responsabilidad patrimonial y la petición indemnizatoria deberá dirigirse siempre ante el Ministerio de Justicia. 
cual procedía del artículo 1.927 del Código Civil, el cual fue derogado al constitucionalizarse la responsabilidad patrimonial del Estado. Tratándose de responsabilidad penal, el Código Penal no presenta una sistematización con la materia civil para entablar la responsabilidad proveniente de un ilícito civil, pues la responsabilidad del juzgador se refiere a delitos sancionados por el artículo $225 .{ }^{17}$

En las disposiciones del ámbito local, los códigos civiles estatales que prevén responsabilidad extracontractual ${ }^{18}$ establecen que el Estado tiene la obligación de responder por los daños causados por sus servidores públicos, y la reparación debe consistir - a elección del ofendido- en el restablecimiento a la situación anterior cuando sea posible o en el pago de daños y perjuicios. Además, son coincidentes ${ }^{19} \mathrm{y}$ establecen que la responsabilidad estatal puede ser subsidiaria y solidaria una vez que se verifique la insolvencia del juzgador; o bien, a la remisión a disposiciones específicas, pues algunos Estados comenzaron a regular la responsabilidad patrimonial por no ser una materia exclusiva de la federación. Sin embargo, estos ordenamientos son heterogéneos en cuanto a sus alcances y a su naturaleza. Como ejemplos, tenemos la ley para exigir responsabilidad patrimonial a jueces y funcionarios del Ministerio Público del Estado de Chihuahua; el artículo 154, fracción 3 de la Constitución Política del Estado de Cohahuila; o el título octavo de la legislación penal para el Estado de Aguascalientes (Romero Michel, 2012).

Esta situación genera derechos para acceder a la justicia y obtener una indemnización en forma muy diversa, no habiendo equidad en su tutela, pues para algunos se estará garantizado el derecho derivado de un error judicial, mientras que, para otros, solo quedará optar por la vía civil con la reparación de daños y perjuicios.

Consideramos que los proyectos legislativos deben examinarse en el marco de las disposiciones de carácter internacional en forma insoslayable, en virtud de que el derecho a la indemnización, cuando se ha sufrido prisión injusta de la libertad, busca mitigar los efectos de los hechos dañinos y otorgar los instrumentos para hacer efec-

17. Delitos contra la administración de justicia cometidos por servidores públicos, y para que se dicte la individualización de las sanciones, el juzgador deberá tomar en cuenta la antigüedad del juez en el empleo, sus antecedentes de servicio, sus percepciones, su grado de instrucción y, por supuesto, la necesidad de reparar los daños y perjuicios causados por la conducta ilícita y las circunstancias especiales de los hechos constitutivos del delito.

18. Excepto Jalisco, Guanajuato y Baja California, que derogaron de sus códigos civiles la obligación que tiene el Estado de responder del pago de daños y perjuicios causados por sus empleados y funcionarios con motivo del ejercicio de sus atribuciones.

19. Se exceptúan Colima, donde la reparación del Estado es objetiva (artículo 1.819 del Código Civil); Coahuila, donde la reparación siempre será solidaria, aun cuando el responsable pueda pagar (artículos 1.865 y 1.866 del Código Civil); Querétaro, donde la reparación es solo solidaria (artículo 1.799 del Código Civil); San Luis Potosí, donde la reparación solo es subsidiaria (artículo 1.764 del Código Civil), y Tamaulipas, donde la reparación es únicamente subsidiaria (artículos 1.409 y 1.410 del Código Civil). 
tiva una reparación integral. Así, la Corte Interamericana de Derechos Humanos, en Loayza Tamayo con Perú, señaló:

La libertad otorgada por el Estado no es suficiente para reparar plenamente las consecuencias de las violaciones de derechos humanos perpetradas contra la víctima [...], la Corte ha tenido en cuenta el tiempo que la víctima permaneció encarcelada y los sufrimientos que padeció, derivados de los tratos [...] a los que fue sometida, como su incomunicación durante la detención, su exhibición con traje infamante a través de los medios de comunicación, su aislamiento [...]. Por lo que resulta necesario buscar formas sustitutivas de reparación, como la indemnización pecuniaria, que se refiere primeramente a los perjuicios sufridos y, como esta corte ha expresado, comprende tanto el daño material como el daño moral. ${ }^{20}$

De igual manera, en Mendoza y otros con Argentina, consideró

que el proyecto de vida atiende a la realización integral de la persona afectada, [... ] Dicho daño se deriva de las limitaciones sufridas por una persona para relacionarse y gozar de su entorno personal, familiar o social, por lesiones graves de tipo físico, mental, sicológico o emocional que se le hayan ocasionado. La reparación integral del daño al "proyecto de vida» generalmente requiere de medidas reparatorias que vayan más allá de una mera indemnización monetaria, consistentes en medidas de rehabilitación, satisfacción y garantía de no repetición. ${ }^{21}$

Lo anterior no quiere decir que la reparación contenga todos los daños posibles, ni que se tenga derecho a ella de manera automática, pues se debe estudiar cada caso en concreto y no suponer que cuando existe una situación similar se presente un perjuicio igual. Su valoración debe considerar la necesidad de ponderar las circunstancias y la posibilidad de no rehabilitar la honorabilidad perdida, y la mayor o menor probabilidad de alcanzar el olvido social del hecho, así como la huella que haya dejado en la personalidad de quien la ha padecido (Fuentes, 1999).

\section{Conclusiones}

El derecho internacional ha desarrollado estándares sobre la remoción de los obstáculos existentes para acceder a la justicia y el derecho a contar con los remedios judiciales o de reparación efectivos. La comunidad internacional, incluido México, aceptaron el desafío de los actuales tiempos al proponer la protección de los derechos humanos garantizando el acceso a la justicia en todos los niveles, con lo que se con-

\footnotetext{
20. Sentencia del caso Loayza Tamayo con Perú, Corte Interamericana de Derechos Humanos, 27 de noviembre de 1998, párrafo 123.

21. Sentencia del caso Mendoza y otros con Argentina, Corte Interamericana de Derechos Humanos, 14 de mayo de 2013, párrafo 314 .
} 
figura este último como un bien jurídico protegido y una obligación erga omnes para los Estados. La eliminación de las barreras legales y procedimentales resulta ser un paso previo que, junto con la creación de diferentes institutos y mecanismos, puede garantizar a las personas el acceso a las vías judiciales.

Como se analizó, en México la interpretación de los compromisos a nivel de derecho internacional que vinculan al sistema jurídico implican eliminar los obstáculos presentes, y aun cuando la Suprema Corte de Justicia sea el máximo tribunal del Estado, justamente al ser parte del Estado mexicano, tiene que dar cumplimiento efectivo de las obligaciones suscritas y no definir en qué casos sí es conveniente y en qué casos no, ya que la violación hacia el derecho humano se manifiesta más allá de la decisión de la Corte Suprema. Por ello, es fundamental garantizar el acceso a la justicia a quien haya sido dañado por el Estado en su función de administrar justicia y más cuando se trata de una privación injusta de libertad, pues el acceso a la justicia es un derecho fundamental que ha sido reconocido como prioridad para los países como un nuevo objetivo de desarrollo sostenible para garantizar sociedades más pacíficas y justas.

\section{Referencias}

Fuentes, Mercedes (1999). «El precio de la libertad: La indemnización por una injusta prisión preventiva». Revista Aranzadi de Actualización Jurisprudencia, 7: 9-19. Disponible en https://bit.ly/2ST3V2u.

González Alonso, Augusto (2008). Responsabilidad patrimonial del Estado en la administración de justicia. Valencia: Tirant Lo Blanch.

Lozano, Rafael, Lucero Cahuana-Hurtado, María Jesús Ríos-Blancas y María GonZÁLEZ-RoBledo (2015). «México ante los objetivos de desarrollo sostenible». En Consejo Nacional de Población, La situación demográfica de México 2015 (pp. 131-146). Ciudad de México. Disponible en http://bit.ly/2yWD5gp.

Mosset ItURRASpe, Jorge (2003). El error judicial. Buenos Aires: Rubinzal-Culzoni. Rodríguez Barba, Fabiola (2016). «México y la Agenda para el Desarrollo Sostenible 2030 de la ONU». Chroniques des Amériques, 16 (1): 1-10. Disponible en http:// bit.ly/2Sch85R.

RODRÍGUEZ RAMOs, Luís (2016). «Apariencia y realidad en la responsabilidad patrimonial del Estado juez (limitada vigencia del artículo $121 \mathrm{CE}$ )». Teoría y Realidad Constitucional, 38: 411-431. DOI: 10.5944/trc.38.2016.18595.

Romero Michel, Jessica Cristina (2012). «Ordenamientos de responsabilidad "patrimonial" en la administración de justicia». De Jure, 3 (8): 132-171. Disponible en http://bit.ly/2OIhLgi.

-. (2013). «Los supuestos de la responsabilidad patrimonial del Estado en el funcionamiento de la administración de justicia reconocidos como derechos humanos en el ámbito internacional». Ciencia Jurídica, 1 (3): 115-134. DOI: 10.15174/cj.v2i1.54. 
ZÚÑIGA URBINA, Francisco (2008). «La acción de indemnización por error judicial: Reforma constitucional, regulación infraconstitucional y jurisprudencia». Estudios Constitucionales, 6 (2): 15-41. DOI: 10.4067/So718-52002008000100002.

\section{Sobre las autoras}

Maria Chiara Marullo es licenciada en Derecho en la Universidad de Bolonia, Italia, y máster en Derecho Internacional y de la Unión Europea de la misma universidad. Máster y doctorado en Estudios de Paz, Conflictos y Desarrollo en la Universidad Jaime I, España. Premio Jaime Brunet a la mejor tesis doctoral a la promoción de los derechos humanos, Universidad Pública de Navarra, España. Investigadora postdoctoral y profesora en la Facultad de Ciencias Jurídicas y Económicas de la Universidad Jaime I. Departamento de Finanzas y Contabilidad, grupo de investigación «Sostenibilidad de las Organizaciones y Gestión de la Responsabilidad Social Mercados Financieros». Profesora ayudante doctora en Derecho Privado Internacional en la Universidad Jaime I, Castellón. Su correo electrónico es marullo@uji.es.

Jessica Cristina Romero Michel es doctora en Derecho por el Doctorado Interinstitucional en Derecho de la Asociación Nacional de Universidades e Instituciones de Educación Superior, México. Maestra en Administración de Justicia por la Facultad de Derecho de la Universidad de Colima, México. Especialista en Relaciones Intergubernamentales por la Facultad de Ciencias Políticas y Sociales de la Universidad de Colima. Investigadora posdoctoral en la Facultad de Derecho de la Universidad de Alicante, España. Diplomado en Derechos Humanos y Juicio de Amparo, Universidad de Colima. Profesora e investigadora de tiempo completo de la Universidad de Colima. Profesora del Centro Didáctico Euroamericano de Políticas Constitucionales de la Universidad del Salento, Italia. Secretaria técnica del Doctorado Interinstitucional en Derecho del Asociación Nacional de Universidades e Instituciones de Educación Superior. Su correo electrónico es jessica_romero@ucol.mx. 
El Anuario de Derechos Humanos es una publicación anual de referencia y consulta en derechos humanos y materias afines, que busca ser un espacio de discusión, difusión y conocimiento de los temas centrales sobre derechos humanos en sus contextos nacional e internacional, poniendo a la disposición del público de manera gratuita los distintos desarrollos doctrinales, jurisprudenciales y legislativos ocurridos en este campo dentro del período anual cubierto por cada edición.

\author{
DIRECTORA RESPONSABLE \\ Nancy Yáñez Fuenzalida \\ EDITOR DE CONTENIDOS \\ Salvador Millaleo \\ SITIO WEB \\ anuariocdh.uchile.cl \\ CORREO ELECTRÓNICO \\ anuario-cdh@derecho.uchile.cl
}

LICENCIA DE ESTE ARTÍ́CULO

Creative Commons Atribución Compartir Igual 4.0 Internacional

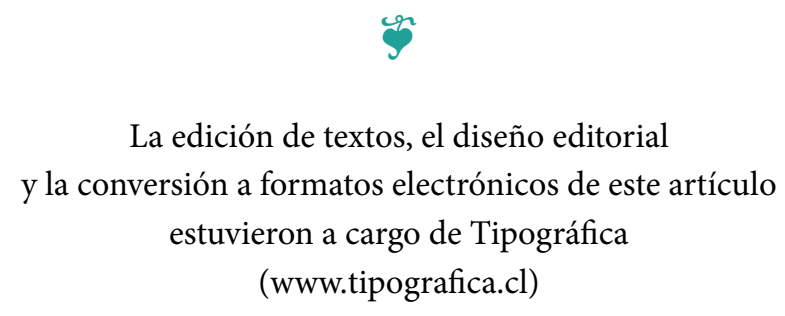

